\title{
Factors which influence necropsy requests: a psychological approach
}

\author{
R D Start, M J Hector-Taylor, D W K Cotton, M Startup, M A Parsons, A Kennedy
}

\begin{abstract}
Aims: To determine which factors influence a clinician's decision to request a necropsy.

Methods: Patient age, confidence in premortem diagnosis, relatives' attitudes, and conditions of necropsy practice were combined factorially (two levels each) in separate medical and surgical questionnaires based on clinical case histories. The interactions between the factors were measured by a repeated measures factorial analysis of variance for each of the two clinical groups. The influence of the clinician's interest in necropsies on these interactions was also examined by a similar method.
\end{abstract}

Results: Necropsies were more likely to be requested on young patients, when diagnostic confidence was low, and when relatives' attitudes were favourable. Conditions of necropsy practice did not affect the likelihood of a request and there was no apparent overall difference in necropsy requests between the two groups of clinicians. The "patient age" and "relatives" factors had less influence on the decision of the surgical group to request necropsy. This was attributed to the opportunity to "see for themselves" at operation and was supported by the finding that surgeons were very likely to request necropsies in the absence of surgical intervention. Clinicians from both groups with a high pre-existing interest in the necropsy were consistently more likely to request necropsies.

Conclusions: The "case history" based questionnaires successfully measured the relative influence of multiple factors in relation to the decision of clinicians to request a necropsy. These findings suggest that any attempt to reverse the decline in necropsy rates should focus on changing the clinician's perception of the value of the modern necropsy.

Over the past 40 years hospital necropsy rates have progressively declined ${ }^{1-3}$ despite a wealth of evidence which indicates the continuing value of necropsies in medical education and research, and in the confirmation of diagnostic accuracy as part of a wider conribution to clinical audit. ${ }^{4}$

Although a wide range of factors has been reported to influence a clinician's decision to request a necropsy, ${ }^{5}$ some measurement of the relative influence of individual factors is required to develop a strategy to reverse the decline in necropsy rates.

Previous enquiries into necropsy request behaviour have relied on questionnaires which required clinicians to answer numerous general questions relating to necropsy practice. $^{6-8}$ These traditional methods of attitude measurement fail to consider the context in which an attitude is developed, held, and then enacted, ${ }^{910}$ but this can be achieved in part using fictitious case histories which allow the clinician to demonstrate his or her attitude in the form of role enactment. ${ }^{11}$ This psychological approach was used for the first time to investigate the interactions between those factors considered to influence a clinician's decision to request a necropsy.

\section{Methods}

Two equivalent questionnaires were constructed for general medical and surgical clinicians to assess the interactions of five factors likely to influence a clinician's decision to request a necropsy. These factors, which were selected after a review of published data by a panel of clinicians, pathologists, and psychologists, were the patient's age, conditions of necropsy practice, attitude of relatives, the clinician's confidence in the premortem diagnosis, and the clinician's general interest in necropsies.

The first four factors were assembled in every possible combination of both positive and negative values into 16 medical and 16 surgical fictitious case histories created from actual patient records. The histories were sequenced randomly with an equal sex distribution; examples are shown in the table.

Each clinician has an individual level of interest in the necropsy, but this should have a consistent influence on that individual's decision to request one. Therefore, it would not be appropriate to vary the level of interest in the same way as for the other four factors in the questionnaires, and a measure of this fifth factor was obtained separately.

\section{CRITERIA}

Age Old patients were defined as those aged 70 and above. Patients aged between 61 and 74 were excluded to separate clearly the old and young groups. Children were not included. Diagnostic confidence "High confidence" cases referred to a confirmed diagnosis or an established complication of a known disease. "Low confidence" cases referred to reasonable doubt in the accuracy of the premortem diagnosis. This group included complex cases with several possible causes of death. 
Examples of clinical case histories

Medical case history

A 39 year old man with known hypercholesterolaemia was admitted with central chest pain. He had had several previous admissions with angina, for which he was on maximal medication. He was awaiting coronary angiography prior to possible coronary bypass surgery. ECG and cardiac enzyme changes, on his admission, revealed an acute myocardial infarction. After two days he suffered a cardiac arrest which was followed by frequent cardiac arrhythmias. Twelve hours later he suffered another cardiac arrest from which he did not recover.

The patient's relatives seem interested in the case, and would, you feel, react positively to a request for autopsy.

The autopsy room is old and in need of modernisation. You have been dissatisfied with autopsies performed at your request in the past and at the delay in receiving a report. Access to past autopsy data is not easily accessible.

WOULD YOU REQUEST AN AUTOPSY?

\begin{tabular}{ccccccc}
\hline $\begin{array}{c}\text { Almost } \\
\text { certainly not }\end{array}$ & & $\begin{array}{c}\text { Not } \\
\text { sure }\end{array}$ & & $\begin{array}{c}\text { Almost } \\
\text { certainly }\end{array}$ \\
\hline 1 & 2 & 3 & 4 & 5 & 6 & 7 \\
\hline
\end{tabular}

Surgical case history

An 82 year old woman was admitted complaining of severe abdominal pain and vomiting. Her medical history included angina cholecystitis, hiatus hernia and cerebrovascular disease. Last year, following a similar episode, she was found to have an abdominal mass, and a caecal filling defect was seen on a barium enema. She declined further investigation at that time. Clinically and biochemically she was markedly dehydrated and hypotensive, with evidence of established heart failure. Although she was willing to accept surgery, her medical conditions necessitated careful preoperative preparation, and she died before surgical intervention could be safely attempted.

The patient's relatives have expressed some interest in the case, and you feel they would react favourably to a request for an autopsy.

The autopsy room is modern and well equipped. There is easy access to past autopsy data. From your experience, previous autopsies have been performed well, and the report arrived promptly.

WOULD YOU REQUEST AN AUTOPSY?

\begin{tabular}{ccccccc}
\hline $\begin{array}{c}\text { Almost } \\
\text { certainly not }\end{array}$ & & $\begin{array}{c}\text { Not } \\
\text { sure }\end{array}$ & $\begin{array}{c}\text { Almost } \\
\text { certainly }\end{array}$ \\
\hline 1 & 2 & 3 & 4 & 5 & 6 & 7 \\
\hline
\end{tabular}

Attitudes of relatives Relatives were stated to favour or to be resistant to the idea of a necropsy, and three equivalent statements conveying these opinions were varied throughout the questionnaires.

Conditions of necropsy practice Necropsy practice conditions were said to be good or bad in a range of statements which included the condition of the mortuary, the standard of necropsies, the delay in receiving a report, and access to necropsy data. In each case history these components were either all negative or all positive.

\section{RATING TECHNIQUE}

The case histories were designed to avoid the necessity of referral for a Coroner's necropsy so that the decision to request a necropsy was at the sole discretion of the respondents. After each case history clinicians were asked how likely they were to request necropsy on a 7 point scale ranging from 1 (almost certainly not) to 7 (almost certainly). Space was available for additional comments.

\section{CLINICIANS' INTEREST IN NECROPSIES}

Clinicians' interest in necropsies was measured separately using three questions concerning their present necropsy request behaviour and their views on the role of the necropsy and its value in clinical practice. The response to each question was scored as "high" or "low" interest on a scale from 1 (low) to 3 (high). The median of the possible total scores was 6 (range 3 to 9). A total score of 7 or above was classified as "high" interest; a score of 6 or less was classified as "low" interest.

Questionnaires were designed to enable the use of a five-way repeated measures factorial analysis of variance to show the main effects of each factor individually and the interactions, within all of the possible combinations, of the four factors studied in both clinical groups. Each of the factors was treated as a repeated measure with two levels, and the additional interactions with the "clinicians' interest" factor was examined using the same method in a second analysis.

A total of 66 clinicians (41 medical, 25 surgical) completed the questionnaires, some after a single reminder. This represented an overall response rate of $61 \%$. All levels of clinician were represented in the sample: consultants $(30 \%)$; senior registrars $(17 \%)$; registrars $(24 \%)$; senior house officers $(15 \%)$; and house officers $(14 \%)$. The sample size was limited by the deliberate restriction of the study to general surgical and medical firms.

\section{Results}

Due to space constraints only the significant results and those which clearly illstrated the patterns found in the other results are presented. A complete set of results and questionnaires is available on request.

No significant main effects or interactions were found when the clinicians were divided on the basis of age, sex, status or employer (NHS or university). The only factor which had no significant main effect on the likelihood of a necropsy request was that relating to necropsy practice conditions. There was no difference in the likelihood of a necropsy request from the medical and surgicial groups, but different interactions between the factors were observed within each clinical group.

Necropsy requests from medical clinicians were more likely if diagnostic confidence was 
low and patients were young. The attitude of relatives did not seem to affect the likelihood of physicians requesting a necropsy when the patient was young, but this was less likely in both clinician groups when the patients were old and the relatives were against a necropsy. Surgeons were more likely to request a necropsy on older patients at both levels of diagnostic confidence when the relatives were in favour, although they were less likely to make a request than physicians in the face of opposition from relatives.

Physicians and surgeons with a high level of interest were more likely to request a necropsy than those with low interest. Under good necropsy practice conditions all clinicians were more likely to request a necropsy when the patient was young rather than when the patient was old. The conditions of necropsy practice seemed to have little influence on necropsy requests from physicians, but a request from surgeons was more likely at both levels of interest when the patient was old and necropsy conditions were bad. The reverse was true when conditions were good.

\section{Discussion}

In contrast to the findings of previous reports, ${ }^{6712-14}$ the conditions of necropsy practice appeared to have no effect on a physician's decision to request one. For the surgical group, necropsy requests initially seemed more likely for old rather than young patients when necropsy conditions were bad and relatives were opposed to the idea. This relation was inconsistent with other results relating to clinical group and necropsy practice conditions, and it seems likely that there was an additional variable influencing the surgeon's decision to request necropsies.

Surgeons seem to have a special interest in necropsies when patients die before surgery or from postoperative complications. This interest incorporates a personal audit of the complications of surgery and the suitability of a surgical treatment. This interest was not anticipated during the construction of the surgical questionnaire, which contained three case histories involving preoperative deaths or surgical complications, all of which coincidentally, presented the conditions of necropsy practice as bad. This boosted surgeons' request rates when necropsy conditions were bad and therefore confirmed that necropsy practice conditions have no effect on the decision to request necropsies.

Although there was no overall difference in the likelihood of a necropsy request between the two groups of clinicians, several combinations of results did seem to indicate that requests may be less likely from surgeons in certain clinical situations. A surgeon can establish the main diagnosis at the time of surgery and this seems to reduce the necessity for a necropsy request except when there are postoperative complications.

All clinicians were generally less likely to request necropsies on older patients, which supports observations that the increasing age of the hospital population contributes to declin- ing necropsy rates. ${ }^{1516}$ Physicians are more likely to request them on young patients, when the patient's age was of greater importance than the attitudes of the relatives. Surgeons seemed to be more influenced by relatives' attitudes to necropsy in young patients, but both physicians and surgeons were influenced by opposition from relatives of older patients, where necropsies did not seem to be of sufficient value to warrant further distress to relatives.

For physicians and surgeons a high degree of confidence in the premortem diagnosis made a necropsy request less likely, and low confidence made a request more likely. This confirms the findings of previous reports which suggest that confidence in the premortem diagnosis is a key factor in a clinician's decision to request a necropsy. ${ }^{6717}$ The increased confidence in the perceived accuracy of clinical diagnoses is a consequence of the new diagnostic techniques available in modern medicine, and many clinicians mistakenly believe that these advances have reduced the value of the necropsy, ${ }^{1819}$ although this contradicts pronounced discrepancies between clinical and necropsy diagnoses in recent studies. ${ }^{131820-26}$

The failure of the medical community to appreciate the role of the necropsy has influenced lay opinion. ${ }^{57-29}$ Relatives are often reluctant to give permission for necropsies, and the widespread lack of proper procedures for obtaining consent must contribute to this antagonism..$^{30-32}$ Although influential in this study, the wishes of relatives seemed to have comparatively little effect on the number of necropsy requests, and in most circumstances diagnostic confidence and patient age were the dominant factors.

The considerable variation in the level of clinicians' interest in necropsies has been widely reported. ${ }^{6334}$ Physicians and surgeons with a high interest in necropsies are consistently more likely to request one than those with low interest, and this finding may have the most practical importance in terms of increasing necropsy request rates. The implication is that it is possible to reverse the decline in necropsy rates by demonstrating the true value of the modern necropsy, particularly in the context of clinical audit. ${ }^{132135}$ The specialist education requirements of different groups of clinicians must also be appreciated.

In reality, such efforts are still unlikely to succeed without an additional central impetus which makes accreditation for training conditional on the demonstration of an adequate necropsy rate within a valid system of audit. ${ }^{36}$

Our "case history" based questionnaires have measured successfully the relative influence of multiple factors in relation to the decision of two groups of clinicians to request necropsies, and have examined the interactions between these factors. Future studies examining the behavioural aspects of hospital necropsy practice would be enhanced by this type of psychological approach.

We thank Dr L E Ramsey, Dr J H F Smith, and Mr C L Welsh for their assistance in the design of the questionnaires, and the many clinical colleagues who participated in the study. 
1 Peacock SJ, Machin D, Duboulay CEH, Kirkham N. The autopsy: A useful tool or an old relic? J Pathol 1988;156: autop.

2 Svendsen E, Hill RB. Autopsy legislation and practice in various countries. Arch Pathol Lab Med 1987;111:846-50.

3 Waldron HA, Vickerstaff $L$. Necropsy rates in United Birmingham Hospitals. BMJ 1975;2:326-8.

4 Hill RB, Anderson RE. The autopsy-medical practice and public policy. Boston: Butterworths, 1988.

5 Roberts WC. The autopsy: its decline and a suggestion for its revival. N Engl J Med 1978;299:332-8.

6 Anderson RE, Hill RB, Gorstein F. A model for the autopsybased quality assessment of medical diagnoses. Hum Pathol 1990;21:174-81.

7 Anderson RE, Hill RB. Epitome. The current status of the autopsy in academic centres in the United States. Am J Clin Pathol 1989;92:s31-7.

8 Cottreau C, McIntyre L, Favara BE. Professional attitudes toward the autopsy. A survey of clinicians and pathologtoward the autopsy. A survey of clinician
ists. Am J Clin Pathol 1989;92:673-6.

9 Harre R, Secord PF. The explanation of human behaviour. Oxford: Basil Blackwell, 1972 .

10 Oppenheim AN. Questionnaire design and attitude measurement.

11 Elstein AS, Shulman LS, Sprafka SA. Medical problem solving, an analysis of clinical reasoning. Massachussets: Harvard University Press, 1978

12 McGoogan E, Cameron HM. Clinical attitudes to the autopsy. Scott Med J 1978;23:19-22.

13 Schned AR, Mogielnicki RP, Stauffer ME. A comprehensive quality assessment program on the autopsy service. Am J Clin Pathol 1986;86:133-8.

14 McPhee SJ, Bottles K. Autopsy: Moribund art or vital science? Am J Med 1985;78:107-13.

15 Ahronheim JC, Bernholc AS, Clark WD. Age trends in autopsy rates. Striking decline in late life. JAMA $1983 ; 250: 1182-6$

16 Cameron HM, McGoogan E, Clarke J, Wilson BA. Trends in hospital necropsy rates-Scotland 1961-1974. BMJ 1975;2:1577-80.

17 Friederici HHR. Reflections on the post-mortem audit. JAMA 1988;250:3461-5.

18 Goldman L, Sayson R, Robbins S, Cohn L, Bettman M, Wiesberg $M$. The value of the autopsy in three medical eras. N Engl J Med 1983;308:1000-5.

19 McGoogan E. The autopsy and clinical diagnosis. J R Coll Physicians Lond 1984;18:240-3.
20 Cameron HM, McGoogan E. A prospective study of 1152 hospital autopsies: II. Analysis of inaccuracies in clinical
diagnoses and their significance. $J$ Pathol 1981;133: 285-300.

21 Cameron HM, McGoogan E, Watson H. Necropsy: a yardstick for clinical diagnoses. BMJ 1980;281:985-7.

22 Mercer J, Talbot IC. Clinical diagnosis: a post-mortem assessment of accuracy in the 1980s. Postgrad Med J 1985;61:713-6.

23 Anderson RE, Hill RB, Key CR. The sensitivity and specificity of clinical diagnostics during five decades. Toward an understanding of necessary fallibility. JAMA 1989;261:1610-7.

24 Harrison $M$, Hourihane DOB. Quality assurance programme for necropsies. J Clin Pathol 1989;42:1190-3.

25 Karwinski B, Hartveit $F$. Death certification: increased clinical confidence in diagnosis and lack of interest in 1989;42:13-7.

26 Puxty JAH, Horan MA, Fox RA. Necropsies in the elderly. Lancet 1983;i:1262-4.

27 McPhee SJ, Bottles K, Lo B, Saika G, Crommie D. To redeem them from death: reactions of family members to autopsy. Am J Med 1986;80:665-71.

28 Brown HG. Lay perceptions of autopsy. Arch Pathol Lab Med 1984;108:446-8.

29 Brown HG. Perceptions of the autopsy: Views from the lay public and program proposals. Hum Pathol 1990;21: $154-8$.

30 Chana A, Rhys-Maitland R, Hon P, Scott P, Thomas C. Who asks permission for an autopsy? $J R$ Coll Physicians Lond 1990;24:185-8.

31 Andersen MN. The problem of autopsy consent in a teaching hospital. J Med Ed 1964;39:518-21.

32 Webster JR, Derman D, Kopin J, Glassroth J, Patterson R. Obtaining permission for an autopsy:-its importance for patients and physicians. Am J Med 1989;86:325-6.

33 King DW. Potential of the autopsy. Arch Pathol Lab Med 1984;108:439-43.

34 Anderson NH, Shanks JH, McCluggage GWG, Toner PG. Necropsies in clinical audit. J Clin Pathol 1989;42: 897-901.

35 Silvestri F, Bussani R, Giarelli L. High autopsy rate in Trieste, 1901-1985: Age associated increase in necroscopy practice. Pathologica 1988;80:523-32.

36 Underwood JCEU, Cotton DWK, Stephenson TJ. Audit and necropsy, Lancet $1989 ; \mathrm{i}: 442$. 